\title{
An Anatomical Insight into the Morphology of the Brachialis Muscle and its Clinical Implications
}

\section{ABSTRACT}

Introduction: Being the chief flexor of the elbow joint, brachialis muscle, also known as 'work horse' of the elbow or Portal's muscle is one of the three muscles of the front of arm. Ascertaining the morphology of the muscle is of considerable clinical significance because infrequent mention of the pathologies like tear, rupture, tendinopathies, etc., coupled with the conflicting reports of its morphology may often leads to inaccurate diagnosis of clinical conditions pertaining to it.

Aim: To study the origin of the muscle in the form of number of heads and type of fibres at origin, site and manner of insertion, mode of nerve supply and presence of accessory slips.

Materials and Methods: The study was carried out in the Department of Anatomy, Parul Institute of Medical Sciences and Research, Parul University, Vadodara on the 82 upper limbs used for routine dissection of first MBBS students. After incising the skin, superficial and deep fascia of the arm and cubital fossa, the biceps was retracted to visualise the origin, insertion and nerve supply of the brachialis muscle.
Results: In all 82 (100\%) arms, the muscle arose by lateral superficial and medial deep heads. Deep head inserted into the coronoid process and upper part of the ulnar tuberosity by an aponeurosis. In 81 (98.8\%) specimens, superficial head was inserted by round tendon on to the ulnar tuberosity distal to the deep head. In one (1.2\%) specimen, fibres of the superficial head were merging with biceps tendon and inserted on to the radial tuberosity. In $75(91.5 \%)$ arms, muscle was supplied by musculocutaneous nerve and radial nerves and in four (5\%) cases by the musculocutaneous, median and Radial Nerve (RN) whereas in $3(3.5 \%)$ case by median and radial nerves. Accessory slips were present in four $(5 \%)$ specimens.

Conclusion: Considerable difference in the morphology of the brachialis was found with regards to the classical picture and should be kept in mind before undertaking any surgical procedure in the arm and elbow region.

\section{INTRODUCTION}

The brachialis muscle, also known as the 'work-horse' [1] of the elbow is one of the three muscles of the anterior compartment of the arm. It is primarily involved in the flexion at the elbow joint as compared to the biceps brachii muscle which is also involved in supination of the radio-ulnar joints. It lies deep to the biceps brachii muscle after taking origin from the anterolateral and anteromedial surfaces of the shaft of the humerus as well as the anterior border and adjoining medial and lateral intermuscular septa below the insertion of the coracobrachialis and deltoid muscles [2]. Thereafter, all the fibres converge below to form elongated and broad tendon which forms the floor of the cubital fossa. The tendon then gets inserted into the anterior surface of the coronoid process and ulnar tuberosity of the ulna [2,3]. Some of its fibres blend with the capsule of the elbow joint, known as Portal's muscle [3]. In the cubital fossa; the Median Nerve (MN), the brachial artery, the biceps tendon and the Radial Nerve (RN) lie anterior to the muscle and the capsule of the elbow joint lies posterior to it. Being a hybrid or composite muscle, it has a dual nerve supply. The Musculocutaneous Nerve (MCN) supplies the major part of the muscle and RN supply small lateral part of muscle [4]. It is the most powerful flexor of the elbow joint in any position of the elbow [4]. However, it has been highly ignored in history and consequently, the literature describing its morphology is relatively very scarce as compared to other muscles. Ascertaining the morphology of the muscle is of considerable clinical significance as infrequent mention of the pathologies like a tear, ruptures, tendinopathies etc., coupled with the conflicting reports of its morphology may often leads to inaccurate diagnosis of clinical conditions pertaining to it $[2,5]$.
The anatomical variations of the brachialis has its imprints in the prenatal life, when at about the fifth week of development a complex interaction between several components, such as the growth factors and pre-adhesion molecules facilitate the migration of the myoblast to the limb buds followed by their orderly and synchronised distribution $[6,7]$. The muscle develops from two fused muscular primordia namely the ventral/flexor and the dorsal/extensor premuscle masses and this is reflected in the dual nerve supply of the muscle. There is an alternate school of thought that believes that the muscle develops solely from the ventral one and the nerves supplying it originates from the ventral division of the brachial plexus and reach the muscle through the RN and supply it [8]. A spate in the study of the muscle has been observed ever since the publication of an article [4] countering the conventional literature described in the standard textbooks and hence, an attempt was made to study the muscle with regards to its various morphological aspects as they could provide valuable insights from the rehabilitation, surgical and radiological point of view [2]. The present study was aimed to evaluate the morphology of brachialis muscle with regards to the site of origin, the number of heads and type of fibres at the origin, insertion of the muscle, nature of insertion (muscular or tendinous or musculotendinous), mode of nerve supply and presence of accessory slips.

\section{MATERIALS AND METHODS}

This prospective, descriptive study was carried out in the Department of Anatomy, Parul Institute of Medical Sciences and Research, Parul University, Vadodara over from 2015-2019 during routine dissection of first MBBS students. Permission from the Institutional Ethics 
Committee (PUIECHR/Letter/Approval/2020/10) was obtained before the commencement of the study. It was conducted on the 82 upper limbs obtained from 41 human cadavers fixed and preserved with $10 \%$ formalin.

The age of the cadavers was between 60 to 90 years. Cadavers with deformity, congenital defects and history of upper limb surgery were excluded from the study. During the dissection of the limb, skin of arm and cubital fossa was incised, superficial fascia and deep fascia was incised and the muscles were exposed. Utmost care was taken to avoid injuring the neurovascular structures. The biceps brachii muscle was either retracted or transacted as and when necessary, in the cubital fossa. Insertion of the coracobrachialis muscle and the deltoid muscle was examined and noted carefully. The origin of the brachialis muscle was noted carefully. Presence of extra heads of the muscle and the manner of their fusion with main muscle belly was examined. In the cubital fossa, insertion of brachialis was observed after retracting its contents and studied. Branches and relations of MCN to brachialis were noted and its course and relations with the other structures were observed. Branches and relations of the RN to the muscle were also observed in front of the elbow by incising the brachioradialis muscle from its origin and the lateral intermuscular septum. In addition to these nerves, any other nerve branches supplying the muscle were also looked for. Any accessory slip from brachialis muscle was looked for and carefully studied.

\section{STATISTICAL ANALYSIS}

Photographs were taken and results were tabulated and analysed accordingly. Data were presented using descriptive statistics.

\section{RESULTS}

Origin: In all the $82(100 \%)$ specimens, the brachialis muscle was found to be arising by two heads: Superficial Head (SH) and Deep head $(\mathrm{DH})$. The $\mathrm{SH}$ was lateral to the $\mathrm{DH}[$ Table/Fig-1,2]. The $\mathrm{SH}$ was found to be arising from the anterior border, the anterolateral aspect of the shaft, in and around the deltoid tuberosity and the lateral inter-muscular septum of the humerus. The $\mathrm{DH}$ was found to be arising from the anteromedial surface of the middle and distal third of the humerus [Table/Fig-1].

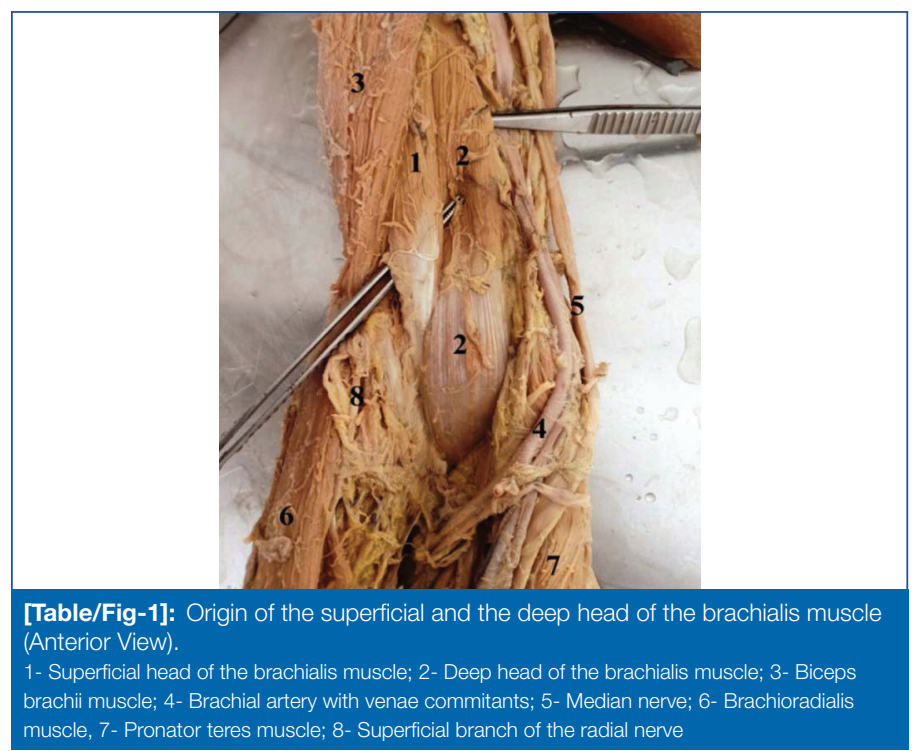

Both the heads arose by fleshy fibres in 75 (91.7\%) specimens. In seven $(8.5 \%)$ specimens, the origin of the $\mathrm{SH}$ was tendinous and in one $(1.2 \%)$ specimen, some fibres of the deltoid muscle were seen merging with it [Table/Fig-2]. The muscle fibres of the $\mathrm{SH}$ were parallel in orientation as they descended downwards and loosely adherent to the bone in the proximal part. The fibres of the $\mathrm{DH}$ were parallel to varying lengths after their origin but as they descended the fibres became oblique converging into an aponeurosis for insertion. They were firmly adherent to the underlying bone. Both the heads were loosely adherent to each other in the proximal part but distally the adjacent fibres were adherent and were blended to variable extents. In three (3.6\%) specimens, the $\mathrm{SH}$ with tendinous origin could be easily lifted from the bone till their insertion and there were no intermingling of superficial and deep fibres.

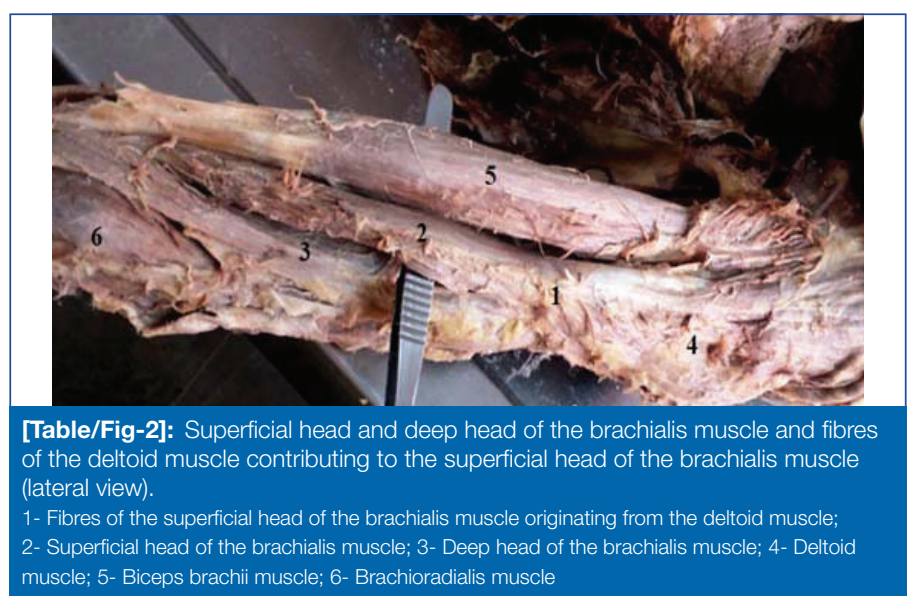

Insertion: In 81 (98.8\%) specimens, the fibres originating from the SH passed downwards and medially and were seen to be inserted onto the ulnar tuberosity by an elongated and round tendon. In all $(100 \%)$ specimen, the fibres of the $\mathrm{DH}$ spread in a fan shaped manner at the cubital fossa and thereafter converged together to form an aponeurosis which was inserted into the coronoid process and the area below it, at times extending onto the upper aspect of the ulnar tuberosity. In all the cases, the insertion of the $\mathrm{SH}$ was found to be more distal than that of the $\mathrm{DH}$ [Table/Fig-3].

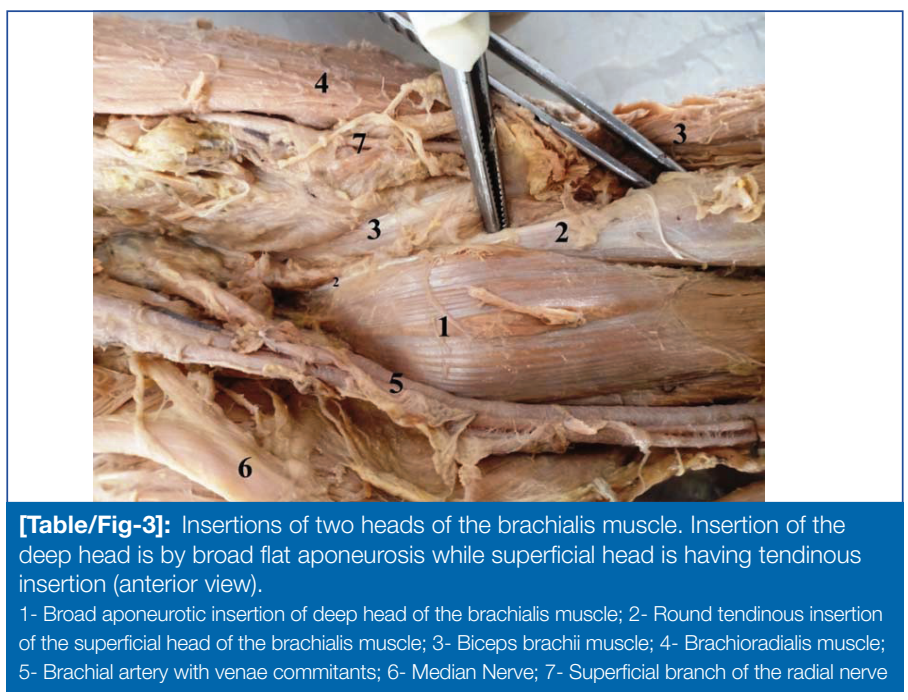

In one (1.2\%) case, the tendon of the SH blended with that of the biceps brachii by a thick aponeurosis and inserted on to the anterior surface of the radial tuberosity which extended upto the anterior border of the radius [Table/Fig-4].

Nerve supply: The $\mathrm{SH}$ and $\mathrm{DH}$ of brachialis were taken as a single unit to study the innervation as the vertical muscular plane between both the heads was not clearly demarcated. In 75 (91.5\%) specimens, the muscle was supplied by the MCN and the RN. In four (5\%) specimens, the muscle was found to be innervated by branches of the MN, the MCN and the RN and in three (3.5\%) specimens; it received innervation from the $\mathrm{MN}$ and the $\mathrm{RN}$.

In all the specimens, the muscle was found to be supplied by the branches of the RN in the infero-lateral part [Table/Fig-5]. Branches of $\mathrm{MCN}$ and the MN, whenever present, entered the muscle in the anteromedial or middle part of the muscle [Table/Fig-6].

Accessory slips: Accessory slips were observed in four (5\%) specimens. In the left upper limb of a male cadaver, two (2.5\%) 

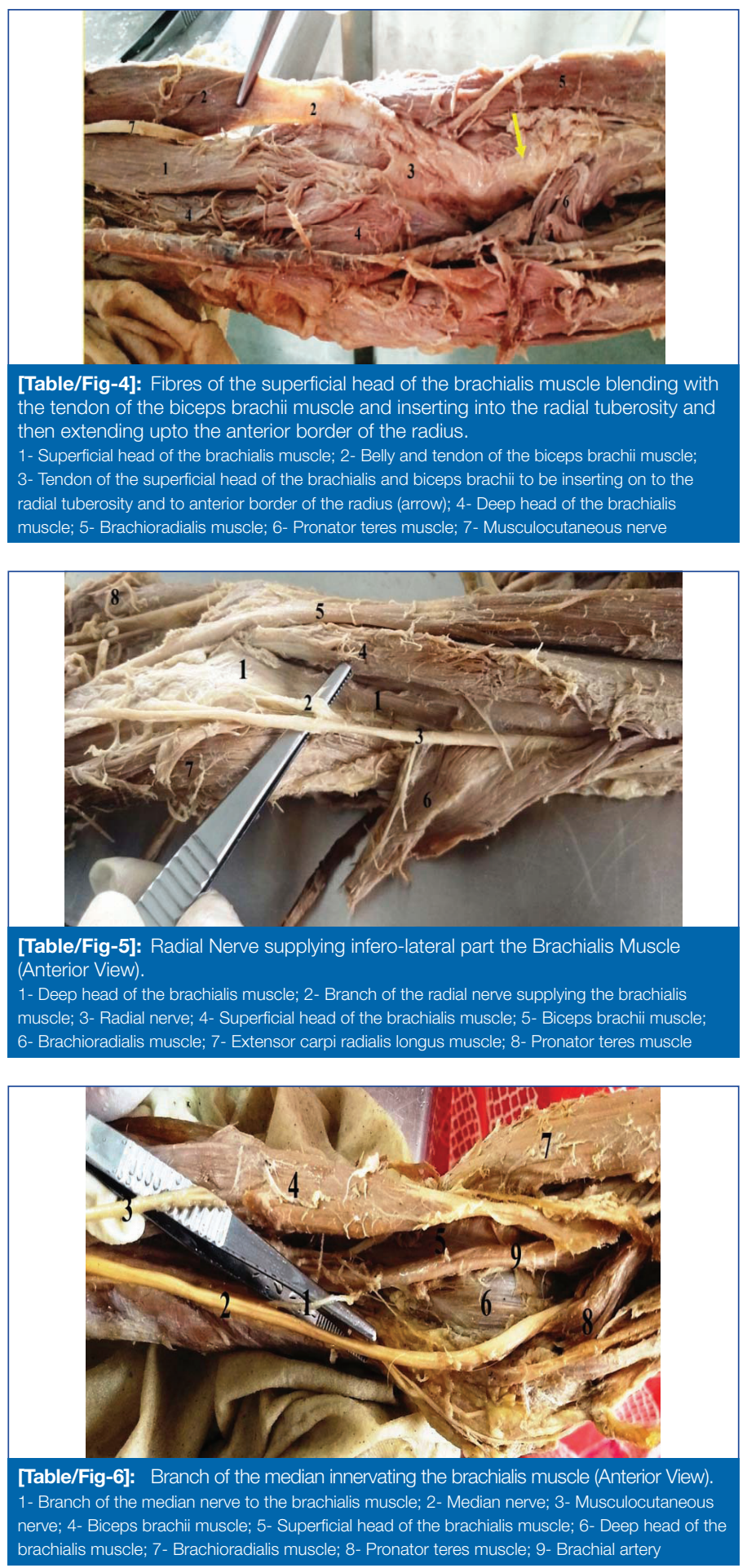

additional slip was seen arising from the $\mathrm{SH}$ of the brachialis muscles and merging with the brachioradialis muscle [Table/Fig-7]. In another two (2.5\%) specimens in the single cadaver, an additional slip from the $\mathrm{SH}$ inserted into the bicipital aponeurosis.

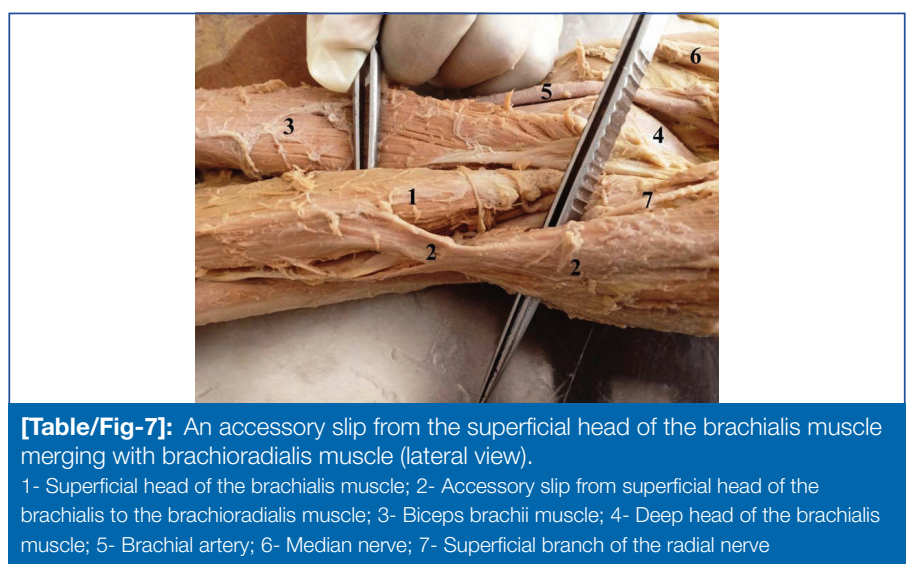

\section{DISCUSSION}

The morphological variations of the brachialis muscle are frequented mostly in the form of accessory slips [1] arising from the adjacent structures and merging with the muscle or vice versa till a decade back when a relook of the anatomy of the muscle revealed that it consisted of two heads; the larger and bulkier $\mathrm{SH}$ and the fan shaped $\mathrm{DH}$. The $\mathrm{SH}$ is lateral and has longitudinal fibres whereas the $\mathrm{DH}$ is medially placed which had oblique fibres $[2,4]$. The insertion of the $\mathrm{SH}$ is at the ulnar tuberosity by a tendon whereas the $\mathrm{DH}$ is attached to the coronoid process of the ulna by an aponeurosis $[4,5,8-10]$. The $\mathrm{SH}$ are mostly fleshy at the origin [4] as found in $91.7 \%$ of specimens in the present study. Tendinous origin of the same was seen in $8.5 \%$ of the cases and has been reported by few other authors $[3,11]$. Converging of adjacent fibres between the two heads as they descend downwards as observed in the present study has also been reported in the literature $[2,5]$.

Sanal HT et al., found that the two heads were easily separable from each other [5]. Some authors believe that the two heads with separate insertions are two separate entities $[2,4]$, performing two different roles functionally: the distal head being responsible for the initiation of flexion from any position of the elbow [4,5] whereas the superficial one is responsible for maintenance of flexion [2,5]. Leonello DT et al., found some fibres from the DH are attached to the capsule of the elbow joint and named them as articularis cubitus [4].

The insertion of the muscles has been described to be either muscular or tendinous or mixed [2]. Some workers have found that it comprises of two elements one tendinous and the other aponeurotic [3]. Both the heads getting inserted to the ulnar tuberosity as a single entity was observed during an Magnetic Resonance Imaging (MRI) study of the elbow joint [5] and in a cadaveric study [3]. Initiation and continuation of elbow flexion could be attributed to the blended nature of the tendons of the $\mathrm{SH}$ and $\mathrm{DH}$ at their insertion [5]. A ruptured tendon of biceps can be attached to that of the brachialis after attaching the latter to the radius with the help of transosseous sutures for restoring flexion of elbow [2,5]. Also, a radiologist should look for brachialis tendon injuries in cases of type three fractures of the coronoid process of the ulna as it more often than not involves the insertion of the brachialis muscle [5].

Detailed knowledge of the morphology of the brachialis and its relations is a pre-requisite for any surgery in this region especially in pediatric patients where supracondylar fracture of the humerus is very common [2]. In the present study, in all the specimens, the insertion of the SH was more distal i.e., at the ulnar tuberosity than the $\mathrm{DH}$ which was seen to be inserted in the coronoid process and upper part of the ulnar tuberosity which was in sync with many authors $[2,4,5,9,10]$. Observations in the present study regarding the insertion of the $\mathrm{SH}$ are consistent with the other authors $[2,4,5]$ except in one (1.2\%) specimen, where the insertion of the $\mathrm{SH}$ extend by an aponeurosis into the anterior part of radial tuberosity and anterior border of the radius. Correlative MRI \& ultrasound is used nowadays to diagnose and differentiate isolated lesions like avulsions and tendinous detachment of brachialis, as its anatomy can be discernible very accurately by these modalities. This in turn could be a decisive factor in choosing between surgical and conservative approaches in management of these injuries [10].

The literature abounds with case reports of accessory slips of the brachialis muscle, which also known as brachialis anticus [1]. In the present study, the accessory slips of origin were found in four (5\%) specimens. The accessory slips of the muscle with regards to origin could have biomechanical consequences, since the elbow joint is also regarded as a buttress [11]. Accessory slips could have a role in restoration and enhancing supination of the forearm, in cases of tendon rupture of the biceps by the reconstruction of the tendon and its subsequent transfer to the radial tuberosity $[2,5,11]$. They could also be used in reconstruction of annular ligament [11]. 
Besides, these accessory slips could give rise to significant signs and symptoms mimicking that of a palpable soft tissue swelling such as fibroma or neuroma, neuropathies due to nerve entrapment under these slips [11]. There are reports of the insertion of the accessory slip onto the radial tuberosity $[1,12-14]$. Merging of the accessory slips of the brachialis to common flexor tendons [14,15], and partially inserting onto the olecranon process [15], brachioradialis [7], radial tuberosity along with biceps $[1,13]$, bicipital aponeurosis [1] has been reported in the literature.

Muscular head arising out of the brachialis and merging with the biceps tendon has been observed and termed as brachiobicipitalis by some authors [11]. The accessory tendons could be of help in restoring the stability of the elbow joint in the form of tendon transfer, in cases of fractures of the coronoid process of ulna $[5,11]$. Besides, these accessory slips can entrap the nerves and vessels passing underneath it during various movements of the arm. Entrapment of the MCN and MN and brachial artery by the accessory head of brachialis has found mention in the recent literature $[11,16,17]$. The comparison of observations of eminent researchers about the origin and insertion of the muscle has been represented in [Table/Fig-8] $[1,2,4,5,9,10]$. Innervation of the brachialis muscle by the $\mathrm{MN}$ is associated with the aberration in the formation or course of the MCN

\begin{tabular}{|c|c|c|c|c|}
\hline $\begin{array}{l}\text { Author, } \\
\text { Year, Type } \\
\text { of study }\end{array}$ & $\begin{array}{c}\text { No of } \\
\text { specimens } \\
\text { (n) }\end{array}$ & $\begin{array}{l}\text { Country } \\
\text { of study }\end{array}$ & Origin & Insertion \\
\hline $\begin{array}{l}\text { Leonello } \\
\text { DT et al., } \\
\text { [4], 2007, } \\
\text { Cadaveric } \\
\text { study }\end{array}$ & 11 & Australia & $\begin{array}{l}\text { Two heads: } \\
\text { Superficial } \\
\text { and Deep }\end{array}$ & $\begin{array}{l}\text { SH- by round tendon } \\
\text { on ulnar tuberosity } \\
\mathrm{DH} \text { - fan shaped } \\
\text { aponeurosis on coronoid } \\
\text { process of ulna }\end{array}$ \\
\hline $\begin{array}{l}\text { Sanal HT } \\
\text { et al., [5], } \\
\text { 2009, MRI. }\end{array}$ & 13 & Thailand & $\begin{array}{l}\text { Two heads: } \\
\text { Superficial } \\
\text { and Deep, } \\
\text { easily } \\
\text { separable }\end{array}$ & $\begin{array}{l}\text { SH- ulnar tuberosity, } \\
\text { distally than } \mathrm{DH} \text {, } \\
\mathrm{DH} \text { - fan shaped on ulnar } \\
\text { tuberosity. Insertion } \\
\text { musculo-tendinous }\end{array}$ \\
\hline $\begin{array}{l}\text { Tafgliafico } \\
\text { A et al., } \\
\text { [10], 2013, } \\
\text { Ultrasound } \\
\text { /MRI }\end{array}$ & 153 & Italy & $\begin{array}{l}\text { Two heads: } \\
\text { Superficial } \\
\text { and Deep }\end{array}$ & $\begin{array}{l}\text { SH- by round tendon, } \\
\text { ulnar tuberosity. Distal } \\
\text { than } \mathrm{DH}, \mathrm{DH} \text { - elongated } \\
\text { and aponeurotic, ulnar } \\
\text { tuberosity medial to } \mathrm{SH} \\
\text { and coronoid process }\end{array}$ \\
\hline $\begin{array}{l}\text { Khandey S, } \\
\text { [1], 2014, } \\
\text { Cadaveric } \\
\text { study }\end{array}$ & 115 & UAE & $\begin{array}{l}\text { Four } \\
\text { accessory } \\
\text { slips }\end{array}$ & $\begin{array}{l}\text { Two slips inserted } \\
\text { from brachialis on } \\
\text { radial tuberosity and } \\
\text { supplied by radial nerve } \\
\text { and another two slips } \\
\text { inserted to the bicipital } \\
\text { aponeurosis }\end{array}$ \\
\hline $\begin{array}{l}\text { llayperuma } \\
\text { I et al., } \\
\text { [2], 2019, } \\
\text { Cadaveric } \\
\text { study }\end{array}$ & 240 & Sri Lanka & $\begin{array}{l}\text { Two heads: } \\
\text { Superficial } \\
\text { and Deep }\end{array}$ & $\begin{array}{l}\text { SH- by thick circular } \\
\text { tendon on ulnar } \\
\text { tuberosity DH- musculo } \\
\text { aponeurotic onto the } \\
\text { anterior surface of the } \\
\text { coronoid process, } \\
\text { inserted as two } \\
\text { separate entities }\end{array}$ \\
\hline $\begin{array}{l}\text { Yamamoto } \\
\text { M et al., } \\
\text { [9], 2018, } \\
\text { Cadaveric } \\
\text { study }\end{array}$ & 22 & Japan & $\begin{array}{l}\text { Two heads: } \\
22.7 \% \text { Three } \\
\text { or four heads } \\
-44.4 \% \\
\text { Multiple heads } \\
-33.3 \%\end{array}$ & Not mentioned \\
\hline $\begin{array}{l}\text { Present } \\
\text { study, } \\
2020 \text {, } \\
\text { Cadaveric } \\
\text { study }\end{array}$ & 82 & India & $\begin{array}{l}\text { Two heads: } \\
\text { Superficial } \\
\text { and deep, } \\
\text { four } \\
\text { accessory } \\
\text { slips }\end{array}$ & $\begin{array}{l}\text { SH- by round tendon, } \\
\text { ulnar tuberosity. Distal } \\
\text { than DHDH- elongated } \\
\text { and aponeurotic, ulnar } \\
\text { tuberosity and upper } \\
\text { part of coronoid process. } \\
\text { Two slips from SH of } \\
\text { brachialis merged with } \\
\text { brachioradialis. Two } \\
\text { another two slips inserted } \\
\text { to bicipital aponeurosis }\end{array}$ \\
\hline \multicolumn{5}{|c|}{$\begin{array}{l}\text { [Table/Fig-8]: Comparison of findings of eminent researchers about the origin and } \\
\text { insertion of the muscle }[1,2,4,5,9,10] \text {. }\end{array}$} \\
\hline
\end{tabular}

[9]. In a recent Korean cadaveric study [18], four types of innervation pattern of the brachialis muscle was observed; Type I- solo innervation by the MCN observed in 25\%, Type II- dual innervation by the MCN and RN seen in 55\%; Type III- innervations by both the MCN and MN found in 15\%; and Type IV- innervation by the MCN and MN and $\mathrm{RN}$ seen in $5 \%$ of the cases [18]. The role $\mathrm{RN}$ with regards to the brachialis muscle is highly contentious. Though it is thought to be purely sensory; newer electrophysiological researches have shown that it might have a motor component as well $[19,20]$.

Contractions were elucidated in the muscle by stimulating the $\mathrm{RN}$ at the spiral groove during surgery [21]. A confirmed lesion of the RN by MRI scans has been associated with the paralysis and subsequent atrophy of the muscle has been reported [20]. Frazer EA et al., found that there was considerable overlapping between the fibres of the MCN and the RN [21]. Splitting the muscle anteriorly would invariably damage the MCN $[22,23]$. It has been well acknowledged by many surgeons that an inner nervous plane exists in the midline of the brachialis with the medial and the lateral part being supplied by the MCN and RN, respectively [23]. A surgeon has to be careful while splitting the plane between the brachialis and brachioradialis as it will put the $\mathrm{RN}$ at risk while splitting the brachialis and would endanger the MCN especially in circumstances when it is the sole nerve supply to the muscle [23]. Comparison in the findings of innervations of the brachialis muscle as found by eminent workers is tabulated in [Table/Fig-9].

\begin{tabular}{|c|c|c|c|}
\hline Authors, Year & $\begin{array}{l}\text { No of specimens } \\
\text { (n) }\end{array}$ & $\begin{array}{l}\text { Country } \\
\text { of study }\end{array}$ & Innervation \\
\hline $\begin{array}{l}\text { Mahakkanukrauh } \\
\text { P et al., [19], } 2002\end{array}$ & 124 & Thailand & $\begin{array}{l}\text { MCN - } 100 \% \\
\text { RN - } 81.6 \%\end{array}$ \\
\hline $\begin{array}{l}\text { Blackburn SC et } \\
\text { al., [23], } 2007\end{array}$ & 42 & $\begin{array}{l}\text { United } \\
\text { Kingdom }\end{array}$ & $\begin{array}{l}\text { MCN }-100 \% \\
\mathrm{RN}-74 \%\end{array}$ \\
\hline $\begin{array}{l}\text { Prakash et al., } \\
\text { [12], } 2009\end{array}$ & 140 & India & $\begin{array}{l}\text { MCN - } 100 \% \\
\text { RN - } 72.14 \%\end{array}$ \\
\hline $\begin{array}{l}\text { Bendersky M and } \\
\text { Bianchi HF [22], } \\
2012\end{array}$ & 20 & Argentina & $\begin{array}{l}\text { MCN }-100 \% \\
\text { RN }-65 \%\end{array}$ \\
\hline $\begin{array}{l}\text { Won SY et al., } \\
\text { [18], } 2014\end{array}$ & 20 & $\begin{array}{l}\text { South } \\
\text { Korea }\end{array}$ & $\begin{array}{l}\text { MCN - 25\% } \\
M C N-25 \% \\
M C N+R N-55 \% \\
M C N+M N-15 \% \\
M C N+M N+R N-5 \%\end{array}$ \\
\hline $\begin{array}{l}\text { Yamamoto M et } \\
\text { al., [9], } 2018\end{array}$ & 9 & Japan & $\begin{array}{l}\mathrm{MCN}+\mathrm{RN}-77.7 \% \\
\mathrm{MCN}+\mathrm{MN}+\mathrm{RN}-11.1 \%\end{array}$ \\
\hline $\begin{array}{l}\text { Present study, } \\
2020\end{array}$ & 82 & India & $\begin{array}{l}M C N+R N-91.5 \% \\
M C N+M N+R N-5 \% \\
M N+R N-3.5 \%\end{array}$ \\
\hline \multicolumn{4}{|c|}{$\begin{array}{l}\text { [Table/Fig-9]: Comparison of findings by eminent authors regarding innervations } \\
\text { of the brachialis muscle }[9,12,18,19,22,23] \text {. } \\
\text { MCN: Musculocutaneous nerve; RN: Radial nerve; MN: Median nerve }\end{array}$} \\
\hline
\end{tabular}

\section{Limitation(s)}

The study was done in cadavers, hence it was not possible to corroborate the findings with the possible signs and symptoms which could arise due to the presence of accessory slips. Presence of an accessory slip could have strengthened the flexion of the arm. Also, it was not possible to find out whether the $\mathrm{RN}$ is motor or sensory to the muscle.

\section{CONCLUSION(S)}

Considerable difference in the morphology of the brachialis was found in the present study as compared to the classical picture found in standard textbooks. And hence, there is a requirement for revising its anatomy. A substantial difference was found in the innervations of the muscle which could be important from the anaesthetic, surgical and orthopaedic point of view and these differences should be kept in mind before undertaking any surgical procedure in the elbow region. It is highly recommended that more anatomical studies are carried out by correlating the gross morphology with ultrasonography, MRI based or EMG data analytical methods. 


\section{REFERENCES}

[1] Khandey S. Morphology of brachialis muscle: Variations and clinical significance. Int J Anat Res. 2014;2:184-86.

[2] Ilayperuma I, Uluwitiya SM, Nanayakkara BG, Palahepitiya KN. Re-visiting the brachialis muscle: Morphology, morphometry, gender diversity, and innervation. Surgical and Radiologic Anatomy. 2019;41(4):393-400.

[3] Kamineni S, Bachoura A, Behrens W, Kamineni E, Deane A. Distal insertional footprint of the brachialis muscle: 3D morphometric study. Anatomy Research International. 2015;2015:786508.

[4] Leonello DT, Galley IJ, Bain GI, Carter CD. Brachialis muscle anatomy: A study in cadavers. JBJS. 2007;89(6):1293-97.

[5] Sanal HT, Chen L, Negrao P, Haghighi P, Trudell DJ, Resnick DL. Distal attachment of the brachialis muscle: anatomic and MRI study in cadavers. American Journal of Roentgenology. 2009;192(2):468-72.

[6] Mehta V, Yadav Y, Arora J, Kumar H, Suri RK, Rath G. Clinico-embryological perspective of a rare accessory brachial muscle with possible musculocutaneous nerve compression. Morphologie. 2009;93(300):27-29.

[7] Misba CA, Rajasekar SS. A slip from brachialis muscle to brachioradialis muscle - a case study. RGUHS Journal of Medical Sciences. 2013;3(4):222-24.

[8] Jayakumar, VR, Bajpe, R, Shubha, R. Variation in the insertion of brachialis muscle - a case report. IJSR. 2013;3:172-75.

[9] Yamamoto M, Kojyo U, Yanagisawa N, Mitomo K, Takayama T, Sakiyama K, et al. Morphology and relationships of the biceps brachii and brachialis with the musculocutaneous nerve. Surgical and Radiologic Anatomy. 2018;40(3):303-11.

[10] Tafgliafico A, Michaud J, Perez MM, Martinoli C. Ultrasound of distal brachialis tendon attachment: Normal and abnormal findings. The British Journal of Radiology. 2013;86(1025):20130004

[11] Mehta VA, Suri RK, Arora JY, Rath GA, Das S. Peculiar tendinous origin of the brachialis muscle: Anatomic and clinical insight. Romanian Journal of Morphology and Embryology. 2009;50(1):141-43.

[12] Prakash, Kumari J, Singh N, Rahul Deep G, Akhtar T, Sridevi NS. A cadaveric study in the Indian population of the brachialis muscle innervation by the radial nerve. Rom J Morphol Embryol. 2009;50(1):111-14.
[13] Srimathi MKT, Ananda Rani VS, Azhagiri R. Clinical and functional significance of the anomalous insertion of the brachialis into the radial tuberosity: A case report. JCDR. 2012;6:116-17.

[14] Sawant SP, Shaikh ST. Additional insertion of brachialis muscle on the radius bone: A case report. Indian Journal of Basic and Applied Medical Research. 2012;2(5):457-59.

[15] George BM, Nayak SB. Median nerve and brachial artery entrapment in the abnormal brachialis muscle - a case report. Neuroanatomy. 2008;7:41-42.

[16] Vadgaonkar R, Rai R, Ranade AV, Nayak SR, Pai MM, Lakshmi R. A case report on accessory brachialis muscle. Rom J Morphol Embryol. 2008;49(4):581-83.

[17] Kumar N, Padur AA, Prabhu G, Shanthakumar SR, Bhaskar R. Rare case of median nerve and brachial artery entrapment by an abnormal musculo-fascial tunnel in the arm: Possible cause of neurovascular compression syndrome. Anatomy \& Cell Biology. 2019;52(1):84-86.

[18] Won SY, Cho YH, Choi YJ, Favero V, Woo HS, Chang KY, et al. Intramuscular innervation patterns of the brachialis muscle. Clinical Anatomy. 2014;28(1):123-27.

[19] Mahakkanukrauh P, Somsarp V. Dual innervation of the brachialis muscle. Clinical Anatomy: The Official Journal of the American Association of Clinical Anatomists and the British Association of Clinical Anatomists. 2002;15(3):206-09.

[20] Spinner RJ, Pichelmann MA, Birch R. Radial nerve innervation to the inferolateral segment of the brachialis muscle: from anatomy to clinical reality. Clinical Anatomy (New York, NY). 2003;16(4):368.

[21] Frazer EA, Hobson M, McDonald SW. The distribution of the radial and musculocutaneous nerves in the brachialis muscle. Clinical Anatomy: The Official Journal of the American Association of Clinical Anatomists and the British Association of Clinical Anatomists. 2007;20(7):785-89.

[22] Bendersky M, Bianchi HF. Double innervation of the brachialis muscle: Anatomicphysiological study. Surgical and Radiologic Anatomy. 2012;34(9):865-70.

[23] Blackburn SC, Wood CP, Evans DJ, Watt DJ. Radial nerve contribution to brachialis in the UK Caucasian population: position is predictable based on surface landmarks. Clinical Anatomy: The Official Journal of the American Association of Clinical Anatomists and the British Association of Clinical Anatomists. 2007;20(1):64-67.

PARTICULARS OF CONTRIBUTORS:

1. Assistant Professor, Department of Anatomy, Parul Institute of Medical Sciences and Research, Vadodara, Gujarat, India.

2. Professor, Department of Anatomy, Parul Institute of Medical Sciences and Research, Vadodara, Gujarat, India.

3. Professor and Head, Department of Anatomy, Parul Institute of Medical Sciences and Research, Vadodara, Gujarat, India.

\section{NAME, ADDRESS, E-MAIL ID OF THE CORRESPONDING AUTHOR:}

Dr. Jaba Rajguru,

G3, Shapath Residency, Karamsad Vidyanagar Road, Anand, Gujarat, India. E-mail: hibiscusemily@yahoo.com
PLAGIARISM CHECKING METHODS: Jain Het al.]

- Plagiarism X-checker: Aug 01, 2020

- Manual Googling: Nov 17, 2020

- iThenticate Software: Jan 15, 2021 (6\%)

\section{AUTHOR DECLARATION:}

- Financial or Other Competing Interests: None

- Was Ethics Committee Approval obtained for this study? Yes

- Was informed consent obtained from the subjects involved in the study? Yes

- For any images presented appropriate consent has been obtained from the subjects.

ETYMOLOGY: Author Origin

Date of Submission: Jul 29, 2020

Date of Peer Review: Oct 07, 2020

Date of Acceptance: Nov 17, 2020

Date of Publishing: Apr 01, 2021 